\title{
Evaluation of Modified Alvarado Score and Ultrasonography for the Diagnosis of Acute Appendicitis
}

\author{
Money Gupta ${ }^{\text {cc }}$, Verinderjit Singh Virdi ${ }^{2}$, Laxmi Agnihotri ${ }^{3}$, Vishal Mandial ${ }^{4}$ \\ ${ }^{1}$ Assistant Prof Pediatric Surgery, Gian Sagar Medical College, Banur, Rajpura \\ ${ }^{2}$ Assistant Prof Pediatrics, Gian Sagar Medical College, Banur, Rajpura \\ ${ }^{3,4}$ Assistant Prof Surgery, MMU Medical College, Kumharhatti,Solan
}

\begin{abstract}
Acute appendicitis is one of the commonest surgical conditions. Diagnosis of this disease still remains a problem. Alvarado score is a clinical scoring system used to diagnose this. Modified Alvarado score alone has sensitivity of 95\% and Ultrasonography has $86 \%$. Combining both the modalities, sensitivity is $86 \%$ but specificity is $100 \%$. Accuracy of positive diagnosis by Alvarado score alone was $71 \%$ and by Ultrasound alone was $85 \%$ in women. This increased to $92 \%$ by combining both. Modified Alvarado score should be combined with Ultrasonography for the diagnosis of acute appendicitis.
\end{abstract}

Keywords: Alvarado score, acute appendicitis, Ultrasonography

Abbreviations: USG- ultrasonography, CT- Computerized tomography, RIF- right iliac fossa, Hb- hemoglobin, BT- Bleeding time, CTclotting time, TLC- total leucocyte count, DLC- differential leucocyte count, C/E- complete examination, FBS- fasting blood sugar, ECGelectro cardiography.

\section{Introduction}

Acute appendicitis is one of the commonest surgical emergencies. Although the mortality and morbidity from appendicitis has decreased in the last 50 yrs, the diagnostic specificity remains low with false positive rate of $20-25 \%$ [1]. Most physicians are familiar with textbook appearance of appendicitis; anorexia, nausea and vomiting associated with periumbilical pain which shifts to the right lower quadrant with tenderness at McBurney's point and leucocytosis. Several investigations like white cell count, ultrasonography, CT scan, can be done to diagnose acute appendicitis with variable accuracy [2].

A scoring system described by Alvarado 1886, was designed to reduce negative appendicectomy rate without increasing morbidity and mortality. It is 10 point scoring system. In his original paper Alvarado recommended an operation for all patients with score 7 or more. Subsequent studies have suggested that Alvarado score alone is inadequate as a diagnostic test but it has been advocated as a means of selecting patients who should undergo imaging [3]

USG with graded compression not only allows confident diagnosis but also offers a quick and noninvasive way by which to demonstrate enlarged mesenteric lymph nodes and mural thickening of terminal ileum [4]. It is accurate in diagnosing those conditions which do not require surgery like ureteric stones and can be used in pregnancy [5]. However, it is strongly operator dependant [6]. In case of equivocal diagnosis of appendicitis, repeated clinical and laboratory examination was useful [7].

Mohanty and Kaushik studied the modified form of Alvarado score [8]. The last criteria of shift to left of neutrophils was omitted because of lack of facilities, instead patients were subjected to USG of abdomen. The combined technique of using both clinical and sonographic criteria significantly improved the diagnostic accuracy especially in females (93.3\%). As studied by Stephens and Mazzucco, ultrasound alone resulted in correct diagnosis in $87 \%$ cases and Alvarado score alone can diagnose $88 \%$ cases [9].

The present study was conducted at Rajindra Hospital, Patiala to evaluate the usefulness of modified Alvarado score and ultrasonography to compare the sensitivity and specificity of both and evaluate the value of using both modalities together.

\section{Material and methods}

Fifty patients admitted with clinical diagnosis of acute appendicitis irrespective of age and sex formed the material of this study. Cases of appendiceal mass and peritonitis were not included. On admission detailed history was recorded and thorough physical examination was done. Alvarado score was calculated.

Symptoms Migratory RIF pain - 1

Anorexia -1

Nausea and vomiting -1

Signs RIF tenderness -1

Rebound tenderness - 1

Increase in temperature -1

Lab findings Leucocytosis (>10,000/cmm) -1

\section{Shift to left -1}

A last criterion was omitted due to non availability of facility in emergency. So, scoring was out of 9 instead of 10 . All patients with Alvarado score $>7$ were subjected to surgery and patients with Alvarado score $<7$ received close 


\section{International Journal of Science and Research (IJSR) \\ ISSN (Online): 2319-7064 \\ Index Copernicus Value (2013): 6.14 | Impact Factor (2014): 5.611}

observation in hospital. However surgery was performed if Alvarado score increased to up to 7 or above. All patients were subjected to USG. Ultrasonographic criteria were:

- Non compressible appendix with diameter $>6 \mathrm{~mm}$ or wall thickness $>3 \mathrm{~mm}$

- Complex mass ( echo poor, asymmetric)

- Loss of contour

- Free fluid

- Local adynamic ileus

- Graded tenderness over McBurney’s point

USG was done with high frequency transducer of 7.5 $\mathrm{MHz}$ with graded compression. Examination was done with machine Philips SDR 1550x P and permanent record was taken with automatic multiformat camera or Sony thermal videographic printer.

Other biochemical tests like Hb, BT, CT, TLC, DLC, Urine $\mathrm{C} / \mathrm{E}$, FBS, Blood urea, Serum creatinine, ECG etc. were done, if required. Surgical exploration if needed was done. Surgical findings were recorded and compared with Alvarado score findings and USG findings. All appendices removed were sent for histopathology. If pathologist reports no evidence of acute inflammation in the organ, the case was designated as false positive appendicectomy. Sensitivity and specificity of modified Alvarado score and USG was calculated separately and after combining both modalities together and was compared with available literature.

\section{Observations and Discussion}

The patients were categorized into three groups- Men - 1, Women -2 , Children - 3. Out of 50 patients $60 \%$ were male, $28 \%$ were female and $12 \%$ were children. Male: female ratio is 2:1 which is comparable with study of Samsi et al [10]. Age range was 5- 50 yrs. Mean age was 25 yrs.

Table 1: Showing symptoms, signs and laboratory findings

\begin{tabular}{|c|c|c|c|c|}
\hline & $\begin{array}{c}\text { Group 1 } \\
(30)\end{array}$ & $\begin{array}{c}\text { Group 2 } \\
(14)\end{array}$ & $\begin{array}{c}\text { Group 3 } \\
(6)\end{array}$ & Overall \\
\hline Migratory RIF pain & $30(100 \%)$ & $14(100 \%)$ & $6(100 \%)$ & $100 \%$ \\
\hline Anorexia & $25(83 \%)$ & $12(85 \%)$ & $4(66.6 \%)$ & $82 \%$ \\
\hline Nausea/ Vomiting & $24(80 \%)$ & $12(85 \%)$ & $5(83 \%)$ & $82 \%$ \\
\hline Tenderness in RIF & $30(100 \%)$ & $14(100 \%)$ & $6(100 \%)$ & $100 \%$ \\
\hline Rebound tenderness & $22(73 \%)$ & $8(57 \%)$ & $4(66 \%)$ & $68 \%$ \\
\hline Elevated temperature & $10(33 \%)$ & $6(42 \%)$ & $4(66 \%)$ & $40 \%$ \\
\hline $\begin{array}{c}\text { Leucocytosis with } \\
\text { total count }> \\
10,000 / \text { cmm }\end{array}$ & $29(96 \%)$ & $11(78 \%)$ & $6(100 \%)$ & $92 \%$ \\
\hline
\end{tabular}

Role of Alvarado score was studied by Saidi and Ghasemi [11]. It was found to have sensitivity of $96 \%$ in males, $58 \%$ in females and $83 \%$ in children. Crnogorac S and Lovrenski $\mathrm{J}$ found that Alvarado score has sensitivity of $87 \%$ and high diagnostic value of $82 \%$ [12]. Following table shows results in our study.
Table 2: Showing results of appendicectomy according to Alvarado score

\begin{tabular}{|c|c|c|c|}
\hline Alvarado score & $\begin{array}{c}\text { Group } \\
1\end{array}$ & $\begin{array}{c}\text { Group } \\
2\end{array}$ & $\begin{array}{c}\text { Group } \\
3\end{array}$ \\
\hline Sensitivity of & $96.29 \%$ & $81.8 \%$ & $100 \%$ \\
\hline Specificity & $66.66 \%$ & $66 \%$ & $100 \%$ \\
\hline Positive predictive value & $92.85 \%$ & $81.8 \%$ & $100 \%$ \\
\hline Overall accuracy & $90 \%$ & $71 \%$ & $100 \%$ \\
\hline
\end{tabular}

Table 3: Comparing study done by Saidi and Ghasemi (2000) with present study.

\begin{tabular}{|c|c|c|c|c|}
\hline Name of study & Sensitivity & Specificity & PPV & Accuracy \\
\hline Group 1 & & & & \\
\hline Saidi and Ghasemi (2000) & $96 \%$ & $95 \%$ & $93 \%$ & $87 \%$ \\
Present study & $96 \%$ & $66 \%$ & $92 \%$ & $90 \%$ \\
\hline $\begin{array}{c}\text { Group 2 } \\
\text { Saidi and Ghasemi (2000) } \\
\text { Present study }\end{array}$ & $58 \%$ & $96 \%$ & $89 \%$ & $82 \%$ \\
\hline $\begin{array}{c}\text { Group 3 } \\
\text { Saidi and Ghasemi (2000) } \\
\text { Present study }\end{array}$ & $83 \%$ & $66 \%$ & $81 \%$ & $71 \%$ \\
\hline
\end{tabular}

The advantages of modified Alvarado score are:

1) A precise decision is made at admission as to which patients need immediate appendicectomy (score $>7$ ) and which needs period of observation (score $<7$ ).

2) The scoring system is highly sensitive for men and children. Sensitivity in men was $96 \%$ and in children was $100 \%$.

3) False positive appendicectomy rate is only $9 \%$ when patients with Alvarado score of 7 or $>7$ are taken up for appendicectomy.

Thus the modified Alvarado score works extremely well in children and men. However, in women sensitivity and specificity is low. Lamparelli et al stated that compared with men, diagnosis of appendicitis in women is twice as likely to be incorrect.[13].

Sensitivity of USG in our study is found to be $86 \%$. This is comparable with studies of Mohanty and Kaushik as $85 \%$ in their study [8]. In our study only 1 false positive case was there. It was case of tubal pregnancy. In this we study we probably visualized an appendix- mimicking structure. Sensitivity of ultrasound was found to be more than $77 \%$ [14]. Rettenbacher $\mathrm{T}$ et al also concluded that even in patients with clinical probability of acute appendicitis, diagnostic imaging should be performed [15]. Ultrasound is more useful in detecting than in ruling out appendicitis [16]

Table 4: Showing results of appendicectomy according to

\begin{tabular}{|c|c|c|c|c|}
\hline USG \\
\hline Ultrasound findings & Group & Group & Group & Overall \\
& 1 & 2 & 3 & \\
\hline True positive & 24 & 9 & 4 & 37 \\
\hline False positive & - & 1 & - & 1 \\
\hline True negative & 3 & 3 & - & 6 \\
\hline False negative & 3 & 1 & 2 & 6 \\
\hline
\end{tabular}

USG with graded compression has three advantages:

1) The distance between transducer and pathologic process is reduced. 


\section{International Journal of Science and Research (IJSR) \\ ISSN (Online): 2319-7064 \\ Index Copernicus Value (2013): 6.14 | Impact Factor (2014): 5.611}

2) The bowel structures are either displaced or compressed which eliminates gas artifacts.

3) The region of maximum tenderness as indicated by the patient with his finger is approached more precisely.

Combining Alvarado score and USG markedly increased diagnostic accuracy. When both were positive 37 true positive cases were there and there was no false positive case. In women it was found to be $92 \%$ which was comparable with the study of Mohanty and Kaushik who found it to be $93.3 \%$.

Table 5: Comparing Alvarado score, USG and both modalities together.

\begin{tabular}{|c|c|c|c|}
\hline & $\begin{array}{c}\text { Alvarado } \\
\text { score }\end{array}$ & USG & $\begin{array}{c}\text { Combining } \\
\text { both }\end{array}$ \\
\hline Sensitivity & $95 \%$ & $86 \%$ & $86 \%$ \\
\hline Specificity & $42 \%$ & $85 \%$ & $100 \%$ \\
\hline Positive predictive value & $91 \%$ & $97 \%$ & $100 \%$ \\
\hline Overall accuracy & $88 \%$ & $86 \%$ & $88 \%$ \\
\hline
\end{tabular}

\section{Summary and Conclusions}

When the modified Alvarado score was combined with USG, diagnostic accuracy is $92 \%$ in females. Specificity of combining both is $100 \%$. When Alvarado score is equivocal, the addition of USG helped to make the diagnosis of acute appendicitis or alternative diagnosis was made.

The modified Alvarado score should be combined with USG for the diagnosis of acute appendicitis. But nothing can replace careful evaluation by an experienced surgeon.

\section{Future Scope}

For more reproducible outcome for the combined usage of modified Alvarado score and USG, an extended study with more no of patients is advisable.

\section{References}

[1] Puylaert JBCM, Rutgers $\mathrm{PH}$ and Lalisang RI: A prospective study of Ultrasonography in the diagnosis of appendicitis. The New England Journal of Medicine 1987; 317(11): 666-669.

[2] Wilcox RT and Traverso LW: Have the evaluation and treatment of acute appendicitis changed with new technology. Surg Clin North Am Dec 1997; 77(6): 1355-1370.

[3] Douglas CD, Macpherson NE and Davidson PM: Randomized controlled trial of Ultrasonography in diagnosis of acute appendicitis, incorporating the Alvarado score. BMJ 2000; 321: 919-922.

[4] Puylaert JBCM: Mesenteric adenitis and acute terminal ileitis: US evaluation using graded compression. Radiology 1986; 161: 691-695.

[5] Hoffmann J and Rasmussen OO: Aids in the diagnosis of acute appendicitis. Br J Surg 1989; 76:774-779.

[6] Ooms HWA, Koumans RKJ and KangYou PJH: Ultrasonography in the diagnosis of acute appendicitis. Br J Surg 1991; 78: 315-318

[7] Andersson RE, Hugander A, Ravn $\mathrm{H}$ et al: Repeated clinical and laboratory examination in patients with an equivocal diagnosis of appendicitis. World J Surg 2000; 24(4): 479-485

[8] Mohanty SK, Kaushik S: Evaluation of modified Alvarado score in decreasing negative appendicectomy rate- Our experience. Ind J Surg 2000; 62(5): 342-343.

[9] Stephens PL and Mazzucco JJ: Comparison of ultrasound and the Alvarado score for the diagnosis of acute appendicitis. Conn Med 1999;63(3): 137-140

[10] Samsi AB, Adarbar NV , Kamat RS: A study of 100 consecutive cases of acute appendicitis with their histological findings. Ind J Surg 1969;31: 574-79.

[11] Saidi RF and Ghasemi M: Role of Alvarado score in diagnosis and treatment of suspected acute appendicitis. Am J Emerg Med 2000;18(2): 1-5

[12] Crnogorac S and Lovrenski L: Validation of the Alvarado score in the diagnosis of acute appendicitis. Med Pregl 2001; 54: 557-561.

[13] Lamparelli MJ, Hoque HM and Pogson CJ: A prospective evaluation of the combined use of modified Alvarado score with selective laparoscopy in adult females in the management of suspected appendicitis. Ann R Coll Surg Engl 2000; 82: 192-195.

[14] Bendeck SE, Nino- Murcia M, Berry GJ et al: Imaging for suspected: Negative appendicectomy and perforation rates. Radiology 2002; 225:131-136 .

[15] Rettenbacher T, Hollerweger A, Gritzmann N et al: Appendicitis: Should diagnosed imaging be performed if the clinical presentation is highly suggestive of the disease? Gastroenterology 2002; 123: 992-998.

[16] Albiston E: The role of radiology imaging in the diagnosis of acute appendicitis. Can J Gastroenterol 2002; 16: 451-463.

\section{Author Profile}

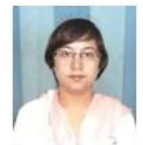

Dr Money Gupta is MBBS, MS (General Surgery) GMC Patiala. MCh (Pediatric Surgery and Pediatric Urology) - PGIMER, Chandigarh. Dr Money Gupta. Dr Money Gupta has completed her M.S (General Surgery) from Govt Medical College, Patiala and subsequently got into M.Ch training in pediatric surgery and pediatric urology in the Department of Pediatric Surgery, PGIMER. She had vast experience for managing neonatal and pediatric surgical emergencies, including Thoracic, GI, Urological, Endoscopy, Laparoscopy and Trauma cases. She is managing good number of elective pediatric surgical cases like undescended testis, hypospadias, pelvic ureteric junction obstruction, vesicoureteric reflux, meningomylocele etc. 